\title{
Evidences of Gentamicin Resistance Amplification in Klebsiella pneumoniae Isolated from Faeces of Hospitalized Newborns
}

\section{Julio César de Siqueira Barros, Sebastião Ronaldo Pinheiro, Marcelo Bozza*, Frederico José Gueiros-Filho**, Alexandre Ribeiro Bello, Ulisses Gazos

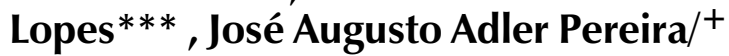

\begin{abstract}
Departamento de Patologia e Laboratórios, Faculdade de Ciências Médicas, UERJ, Av. 28 de Setembro, 87 - fundos, 20551-030 Rio de Janeiro, RJ, Brasil *Laboratório de Farmacologia Aplicada, Far-Manguinhos, Fiocruz, Rio de Janeiro, RJ, Brasil **Harvard University, Biolabs, Cambridge, MA, USA ***Laboratório de

Parasitologia Molecular, Instituto de Biofísica Carlos Chagas Filho, UFRJ, Rio de Janeiro, RJ, Brasil
\end{abstract}

The intestinal microbiota, a barrier to the establishment of pathogenic bacteria, is also an important reservoir of opportunistic pathogens. It plays a key role in the process of resistance-genes dissemination, commonly carried by specialized genetic elements, like plasmids, phages, and conjugative transposons.

We obtained from strains of enterobacteria, isolated from faeces of newborns in a university hospital nursery, indication of phenothypical gentamicin resistance amplification (frequencies of $10^{-3}$ to $10^{-5}$, compatible with transposition frequencies). Southern blotting assays showed strong hybridization signals for both plasmidial and chromossomal regions in DNA extracted from variants selected at high gentamicin concentrations, using as a probe a labeled cloned insert containing aminoglycoside modifying enzyme (AME) gene sequence originated from a plasmid of a Klebsiella pneumoniae strain previously isolated in the same hospital. Further, we found indications of inactivation to other resistance genes in variants selected under similar conditions, as well as, indications of co-amplification of other AME markers (amikacin).

Since the intestinal environment is a scenario of selective processes due to the therapeutic and prophylactic use of antimicrobial agents, the processes of amplification of low level antimicrobial resistance (not usually detected or sought by common methods used for antibiotic resistance surveillance) might compromise the effectiveness of antibiotic chemotherapy.

Key words: resistance amplification - aminoglycosides modifying enzymes - Klebsiella pneumoniae

Antimicrobial resistance, often in the form of multiresistance, poses a special problem for the right choice of agents used for the treatment of nosocomial infections (Jacoby \& Archer 1991, Chopra 1992, Silver \& Bostian 1993). It also creates a favorable condition to the antimicrobial selection and co-selection of resistant bacteria present in the various anatomical sites ordinarily colonized (Baquero et al. 1997). The reactivity and flexibility of the DNA as the basis of genetic information, and the existence of specialized genetic elements involved in DNA recombinations, as an instance of molecular parasitism (such as insertion sequences and

\footnotetext{
This work was supported by CNPq, and SR2/UERJ. ${ }^{+}$Corresponding author. Fax: $+55-21$ - 587.6476. E-mail: josep@uerj.br

Received 19 February 1999

Accepted 7 July 1999
}

transposons), favors the emergence of true bacterial antimicrobial resistance gene blocks, which have been identified endemically and epidemically during the last decades (Schmitt 1986, Tolmasky et al. 1988, Bennett \& Hawkey 1991).

An issue that has a great importance in the phenomenon of antimicrobial resistance is the mechanism of gene transfer among bacteria, involving genetic elements like plasmids and conjugative transposons (Thompson 1986). It has also been shown by Datta and Hughes (1983) that the plasmids carrying multiple resistance genes were not different, in terms of incompatibility groups, from those commonly found in the pre-antibiotic era, and that, often, the resistance genes to antimicrobial agents carried by transposons established themselves in plasmids.

The evolutionary convergence, seen in the form of a frequent and progressive bacterial multiresistance found during the last decades, especially in nosocomial environments, seems to take place more 
widely, involving genes that confer other advantageous features to bacterial survival (colonization/ virulence factors) and that increase the risk for the host (Harihan \& Weinstein 1996).

Since the late 60 s, it has been realized the enormous importance of the colonization of human skin and mucosae as an antecedent to the process of nosocomial infection (Phillips \& French 1996). As the resistant bacterial strains reach the condition of survival in the hospital environment, they can be disseminated, colonizing various anatomical sites of hospitalized patients, especially through the transmission by the hands of hospital personnel (Casewell \& Phillips 1977). These strains can establish themselves as part of the microbiota associated to skin and mucosae, especially in the intestines.

It is accepted that under these circumstances the rising of resistant bacterial population growth may occur, as a consequence of selective pressure due to antimicrobial therapy. Additionally, the microbial interaction at these levels favors the in vivo plasmid transfer. There can be the coexistence of different plasmids belonging to different plasmid incompatibility groups in the bacterial host cell, which promotes genetic recombination, in the form of integration and transposition mechanisms (Nies et al. 1986).

In the hospital environment related to this study, as well as in similar hospitals, this convergence in multiresistance is often associated to gentamicin resistance (Pereira 1990), both in enterobacteria and in other gram negative rods. Gentamicin resistance, and resistance to other aminoglycosides, is often due to the expression of a variety of modifying enzymes (AME, i.e., aminoglycoside modifying enzymes: acetylases, phosphorylases, and adenylases), which can impair the effectiveness of antibiotics (Shaw et al. 1993). Other resistance mechanisms include changes in bacterial membrane permeability and altered ribosomal proteins (Shalaes \& Rice 1996).

In a previous study (Vieira et al. 1999) we have found that about half of the analyzed newborns in a university hospital nursery showed enterobacteria (mostly Klebsiella pneumoniae strains) in their faeces exhibiting resistance to gentamicin and to other antimicrobial agents. Colonization by resistant enterobacteria was associated with previous antimicrobial therapy. We detected single plasmids of high molecular weight in the extracts of the $K$. pneumoniae wild type strains, as well as, for the respective Escherichia coli transconjugants both displaying broad spectra of resistance to the studied antimicrobial agents.

We have found indications of phenotypic amplification of gentamicin resistance in some of the isolated faecal strains, and have sought, specially for one of them, to further characterize aspects of the process, taking into account its possible clinical and epidemiological implications for the transmission of resistance to antimicrobial agents in hospital environments. We believe that this approach can contribute to an assessment of the possible role of low level bacterial resistance in the dynamics of antimicrobial resistance emergence and dissemination.

\section{MATERIALS AND METHODS}

Strains - K. pneumoniae isolated from faeces of newborns hospitalized in the neonatal unit of the State of Rio de Janeiro University Hospital Pedro Ernesto (HUPE/UERJ), strains AS15-G6C and MS16-G5C (Vieira et al. 1999). Both strains were resistant to the antimicrobial agents ampicillin, cephalotin, gentamicin, kanamycin, chloramphenicol, tellurite, displayed intermediary resistance to amicacin and, were sensitive to tetracyclin. E. coli HB101 harboring a pUC18 derivative plasmid containing gentamicin resistance gene (denominated pUJ401F10) originated from the plasmid pKP401F10 of $K$. pneumoniae (original strain isolated from faeces of a patient with urinary infection at HUPE/ UERJ) (Pereira 1990). Distinct clones of E. coli K12 $\mathrm{F}^{-}$transconjugant strains $(1 / 1,1 / 15$ and $1 / 18)$ derived from the mating of the K. pneumoniae AS15G6C strain with the E. coli K12 reference strain, containing multiresistance codifying plasmids, including gentamicin resistance.

Estimates of the frequencies of resistant colonies grown at different concentrations of gentamicin in agar plates - Starting from cultures grown overnight in Mueller Hinton Agar (MHA - Merck) containing $100 \mu \mathrm{g} / \mathrm{ml}$ of ampicillin (Ceme), we performed the inoculation of colonies in Brain Heart Infusion broth (BHI, Difco). After $18 \mathrm{hr}$ growth at $37^{\circ} \mathrm{C}$, suspensions were diluted in sterile saline $(0.85 \% \mathrm{w} / \mathrm{v})$, plated onto Mueller Hinton Agar (in duplicates) containing $8,16,32,64$ or $128 \mu \mathrm{g} / \mathrm{ml}$ of gentamicin and MHA without gentamicin (control). Aliquots of $0.1 \mathrm{ml}$ of the dilutions were adjusted for obtaining bacterial counts ranging from 30 to 300 colonies, to be used for the estimation of the colony forming units (CFU) resistant to the antimicrobial agent. Strains selected at a given gentamicin concentration were subsequently cultured in this same gentamicin concentration to test for reversion of amplification. Modifications in specific steps of the protocol were made to control for possible interference in the tests: (i) use of MHA without ampicillin in the first step, (ii) bypass of the second step, i.e., directly subculturing the strains grown in MHA with ampicillin $100 \mu \mathrm{g} / \mathrm{ml}$ onto MHA with gentamicin, (iii) use of the bulk of a single colony when inoculating the strains into BHI broth to identify possible heterogeneities regarding the level of gen- 
tamicin resistance within the colonies and, (iv) use of $1 \mu \mathrm{g} / \mathrm{ml}$ of gentamicin in the BHI broth overnight step to test for possible resistance induction.

Semi-quantitative evaluation of the frequency of resistant colonies for variants of $K$. pneumoniae AS15 previously selected at different concentrations of gentamicin - The bacterial strains studied were compared regarding their resistance to different gentamicin concentrations, encompassing their amplification potential, by streaking the strains on MHA with increasing gentamicin concentrations. Especially for the K. pneumoniae AS15 strain, this procedure was used to evaluate the ability of a variant strain, selected at a high gentamicin concentration, to show an increase in the frequency of resistance when compared to a non selected AS15 strain.

Sensitivity test to antimicrobial agents (STA) by diffusion in MHA - These tests were performed according to (Bauer et al. 1966) using commercial disks (ampicillin, amikacin, chloramphenicol, gentamicin, tetracyclin). Additionally, the sensitivity tests were performed with highly concentrated antibiotic disks embedded with the following antimicrobials concentrations: gentamicin, $10 \mathrm{mg} / \mathrm{ml}$, trimethoprim-sulphamethoxazole, $50 \mathrm{mg} / \mathrm{ml}$; cefalotin, $125 \mathrm{mg} / \mathrm{ml}$; potassium tellurite, $2.5 \mathrm{mg} / \mathrm{ml}$; chloramphenicol, $125 \mathrm{mg} / \mathrm{ml}$; tetracyclin, $25 \mathrm{mg} / \mathrm{ml}$; amikacin, $30 \mathrm{mg} / \mathrm{ml}$ (usual concentration).

DNA extraction and Southern blotting transfer - Bacterial DNA was extracted according to the technique of Kado and Liu (1981). Plasmidial DNAs were electrophoresed onto $0.8 \%$ gels, transferred to nitrocelulose membranes according to Southern with modifications (Maniatis et al. 1982), and sequentially soaked on $1 \mathrm{M} \mathrm{HCl} / 10 \mathrm{~min}, 0.5 \mathrm{~N} \mathrm{NaOH} /$ $10 \mathrm{~min}$, and, finally, on $1 \mathrm{M}$ Tris. $\mathrm{HCl}, \mathrm{pH} 8.0 / 20 \mathrm{~min}$. Capillary transfer of DNAs was performed with 20 $\mathrm{X}$ SSC solution. The DNAs were bound to the membrane by baking in a vacuum oven at $80^{\circ} \mathrm{C}$ for $2 \mathrm{hr}$.

DNA hybridization assays - The radioactive detection of homologous DNA sequences was carried out with a $13.5 \mathrm{~kb}$ Eco RI fragment probe, containing the gene for an aminoglycoside modifying enzyme originally isolated from $K$. pneumoniae native plasmid (pKP401F10). Random primer labeling of the mentioned probe was carried out with ${ }^{32}$ P-dATP (Feinberg \& Vogelstein 1983). The membranes were sealed on poliethylene plastic bags filled with $5 \mathrm{X}$ SSPE buffer ( $1 \mathrm{X}$ SSPE $=0.18 \mathrm{M} \mathrm{NaCl}$, $10 \mathrm{mM} \mathrm{NaH}_{2} \mathrm{PO}_{4}, 1 \mathrm{mM}$ EDTA, pH 7.0, 0.3\% SDS, $100 \mu \mathrm{g}$ of salmon sperm DNA, type III, SIGMA) per $\mathrm{ml}$ of hybridization solution, $50 \%$ of formamide and pre-hybridized at $42^{\circ} \mathrm{C}$ for at least $3 \mathrm{hr}$. The hybridization step was carried out overnight, at $42^{\circ} \mathrm{C}$, following the addition of $0.5 \times 10^{6} \mathrm{dpm} / \mathrm{ml}$ of the labeled probe, denatured by heat. After the incubation, the membranes were washed four times, for
$15 \mathrm{~min}$, in $250 \mathrm{ml}$ of $2 \mathrm{X}$ SSPE buffer containing $2 \%$ of SDS at $42^{\circ} \mathrm{C}$ with agitation (Martinez-Salazar et al. 1986). The excess of liquid was drained out and, the filters subjected to autoradiography with an intensifying screen at $-70^{\circ} \mathrm{C}$ with the use of a Kodak XAR-5 film. Overnight or longer exposures of the films were carried out.

\section{RESULTS}

We observed that, as the gentamicin concentration increased, the frequency of resistant CFU (colony forming units) decreased progressively from frequencies around $10^{-1}$ for $8 \mu \mathrm{g} / \mathrm{ml}$ to $1 \times 10^{-6}$ $-1 \times 10^{-7}$ at $128 \mu \mathrm{g} / \mathrm{ml}$ of gentamicin (Table I).

\section{TABLE I}

Determination of the frequency of gentamicin resistant colony forming units (cfu) for the Klebsiella pneumoniae AS 15 by plating on gentamicin containing Mueller Hinton agar

\begin{tabular}{crrrr}
\hline $\begin{array}{l}\text { Gentamicin } \\
(\mu \mathrm{g} / \mathrm{ml})\end{array}$ & \multicolumn{4}{c}{ Cfu frequency for the } \\
\hline 8 & \multicolumn{1}{c}{ AS15 strain ${ }^{a}$} & & \\
16 & $10^{-2}$ & 1 & $9 \times 10^{-1}$ & $3 \times 10^{-1}$ \\
32 & $6 \times 10^{-5}$ & $10^{-3}$ & $10^{-2}$ & \\
64 & $2 \times 10^{-5}$ & $4 \times 10^{-4}$ & & \\
128 & $10^{-5}$ & $5 \times 10^{-5}$ & & \\
\hline
\end{tabular}

$a$ : the range of frequencies for the same concentration indicate results from different experiments.

The test of sub-culturing the AS15 variant strains (i.e., AS15 previously selected at gentamicin concentrations higher than $8 \mu \mathrm{g} / \mathrm{ml}$ ) in culture medium with the same gentamicin concentrations as that of the previous selection indicated reversion of amplification events for some $K$. pneumoniae variant strains. The variant selected at $32 \mu \mathrm{g} / \mathrm{ml}$ displayed a frequency of resistant colonies of 3$6 \times 10^{-3}$, and the variant selected at $128 \mu \mathrm{g} / \mathrm{ml}$ displayed a frequency of $5 \times 10^{-3}$. Nevertheless, the frequencies were higher than those of the non-previously selected variant strains.

We did not find differences in the frequency of resistant CFU when previously culturing the strains in medium with ampicillin $(100 \mu \mathrm{g} / \mathrm{ml})$ or without it. Both procedures determined equal frequencies of resistant cells at $8 \mu \mathrm{g} / \mathrm{ml}\left(1 \times 10^{-2}\right)$ and at $16 \mu \mathrm{g} / \mathrm{ml}$ $\left(6 \times 10^{-5}\right)$. The use of a limited portion of a single colony when sub-culturing it overnight into BHI did not lead to different resistant CFU frequencies from those observed when we took a whole colony. At the gentamicin concentration of $64 \mu \mathrm{g} / \mathrm{ml}$, using a whole colony, with previous BHI overnight growth, 
we found the frequency of resistant colonies of $9 \times 10^{-5}$; and with the same gentamicin concentration, also using a whole colony, but sub-culturing it after suspending it in saline solution, we found frequencies compatible with the usual survival rates found for this antibiotic concentration. In the test attempting to identify a possible interference induction of the gentamicin resistance amplification resulting from previous exposure to sub-inhibitory concentrations of this antibiotic, we did not find differences between previously exposed bacteria and non previously exposed ones (data not shown).

In the semi-quantitative tests, performed to verify if previous gentamicin selection would contribute to higher survival rates when challenging the bacteria with higher gentamicin concentrations, we could verify a generalized feature of resistance increase, displayed by the previously selected variant strains. In other words, the higher gentamicin concentration used in the previous selection, the higher density of bacterial growth. Although we have observed a decrease in the frequency of resistant colonies in the reversion assays, as a rule, the density of growth at concentrations equal to those used in the previous selection was indistinguishable from that of the control medium without antibiotic (Table II). We also used this methodology as a means of evaluating comparatively the behavior of other $K$. pneumoniae strains (other than the AS15 strain) facing the same challenge. Almost all of the other $K$. pneumoniae strains studied exhibited confluent growth in MHA containing 128 $\mu \mathrm{g} / \mathrm{ml}$ of gentamicin, hampering a comparative analysis (data not shown).

In the sensibility tests using high concentration antibiotic discs, except for amikacin and gentamicin itself, we did not notice indications of resistance amplification or co-amplification. We obtained, however, indications of possible inactivations of the resistance affecting chloramphenicol (strain variant A32, enlargement of inhibition zone diameter from $12 \mathrm{~mm}$ to $33 \mathrm{~mm}$; variant strains A2048/1 and A2048/5, enlargement of inhibition zone diameter from $12 \mathrm{~mm}$ to $17 \mathrm{~mm}$, and from $12 \mathrm{~mm}$ to $16 \mathrm{~mm}$ respectively). We also identified the presence of sub-populations (usually outlined as an easily identifiable secondary inhibition zone extending beyond the sensibility inhibition zone) with relatively uniform profiles of increased sensibility to several resistance markers (trimethoprimsulphamethoxazole, cefalotin, chloramphenicol, amikacin, and gentamicin) (Table III).

Several electrophoretic analyses of the DNA content for $K$. pneumoniae as well as for transconjugant $E$. coli variant strains, grown overnight at high gentamicin concentration $(128 \mu \mathrm{g} / \mathrm{ml}$ of gentamicin), revealed frequent alterations in plasmid profiles (as opposed to non-selected variant strains, which exhibited single high molecular weight plasmids), indicating possible DNA rearrangements in the course of the amplification events (Fig. 1). The results of these analysis were quite variable and non reproducible, reinforcing the unstable nature of the phenomenon.

A $13.5 \mathrm{~kb}$ Eco RI insert cloned into pUC18, consisting of a K. pneumoniae plasmid fragment carrying aminoglycoside resistance gene(s), including gentamicin resistance, was used as radiolabeled probe in hybridization assays with DNA transferred by Southern blotting. It enabled us to detect (in the region corresponding to plasmid DNA, and also to chromosomal DNA) a signal for gentamicin selected variant strains stronger than for non selected ones (Figs 2A, 2B).

\section{TABLE II}

Sensitivity test for Klebsiella pneumoniae AS15 strain previously selected on several gentamicin concentrations by plating on Mueller Hinton agar containing increasing concentrations of the antimicobrial agent

\begin{tabular}{clc}
\hline $\begin{array}{c}\text { Gentamicin } \\
(\mu \mathrm{g} / \mathrm{ml})\end{array}$ & Strains ${ }^{a}$ & $\begin{array}{c}\text { Intensity of } \\
\text { growth }{ }^{2}\end{array}$ \\
\hline \multirow{3}{*}{128} & A & ++ \\
& A32 & +++ \\
& A64 & ++++ \\
A128 & +++++ \\
\hline \multirow{2}{*}{256} & A & + \\
& A32 & ++ \\
& A64 & +++ \\
& A128 & +++++ \\
\hline \multirow{4}{*}{1024} & A & - \\
& A32 & - \\
& A64 & + \\
& A128 & + \\
& A256 & +++ \\
A1024 & +++++ \\
\hline \multirow{4}{*}{1960} & A & - \\
& A32 & - \\
& A64 & - \\
& A128 & - \\
& A256 & ++ \\
& A1024 & +++++ \\
\hline
\end{tabular}

a: strain A: not selected $K$. pneumoniae AS15 strain; strains A32, A64, A128, A256, and A1024: AS15 strain selected respectively in media with $32,64,128,256$, and $1024 \mu \mathrm{g} / \mathrm{ml}$ of gentamicin; $b$ : intensity of growth (obtained by streaking out a minimal amount of cells with a bacteriological loop); null, no growth: -; almost null, with a few colonies near the initial inoculum site: + ; a higher number of colonies in the initial inoculum site, dispersed through out the seeded area: ++; a higher number of colonies all over the seeded area: +++; quasi confluent growth: ++++ and confluent growth: +++++. 


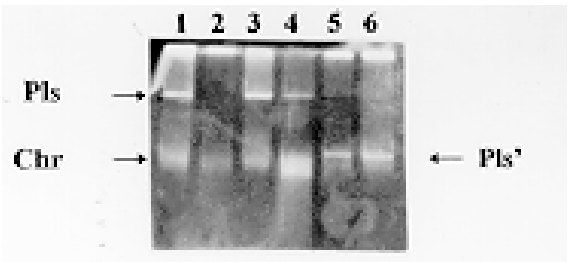

Fig. 1: plasmid profile of variant strains of Escherichia coli transconjugants (Klebsiella pneumoniae x E. coli K12) carrying gentamicin resistance gene and selected, or not, at high concentration of gentamicin. Plasmidial DNAs extracted from E. coli transconjugant variants (Kado \& Liu 1981) were electrophoresed on $0.8 \%$ agarose gel. Chr: chromossomal DNA; Pls: wild type plasmid; Pls': recombinant plasmid. Number in parentheses denote different colonies of $E$. coli transconjugants, 1 (1/1), 2 (wild type, $E$. coli $\mathrm{K} 12), 3$ (1/15) and 4 (1/18), unselected variants, 5 (1/ 15) and $6(1 / 18)$, variants grown overnight at $128 \mathrm{mg} / \mathrm{ml}$ of gentamicin.

\section{DISCUSSION}

The frequency of production of variants for the $K$. pneumoniae AS15 strain indicate a mutation process probably different from spontaneous point mutation. Transposition or site specific mutation involving resistance genes is an event ranging from $10^{-5}$ to $10^{-3}$ "hops" per cell (Schmitt 1986, Wiedemann et al. 1986). Further support for this interpretation are the occurrence (and also the rates) of reversion effects towards antibiotic sensitivity, observed when evaluating the frequency of colony forming units resistant to gentamicin concentrations in the same concentrations used in the previous selection of these same AS15 variant strains. The systematic production of AS15 variant strains with increased resistance at relatively high frequencies, as opposed to other Klebsiella strains, ap-

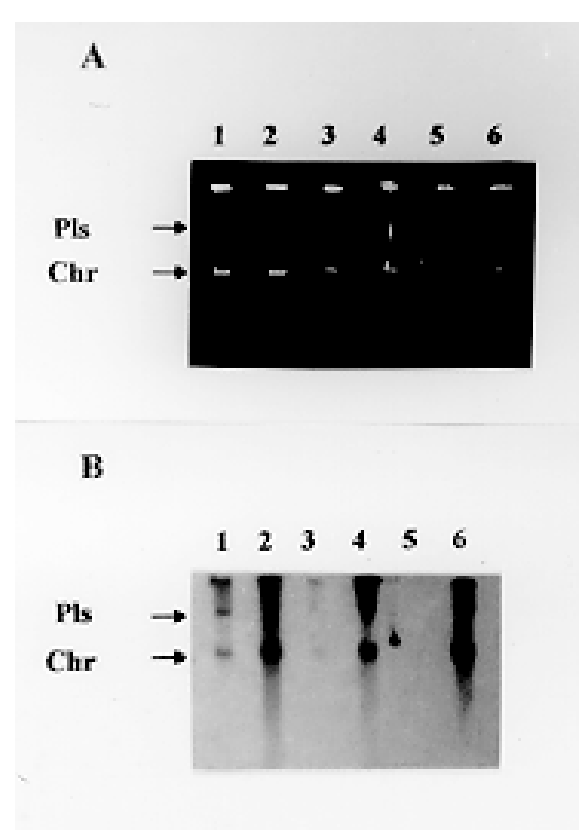

Fig. 2: amplification of gentamicin resistance gene in selected Klebsiella pneumoniae and Escherichia coli transconjugant variants. A: agarose gel electrophoresis $(0.8 \%)$ from Kado and Liu (1981) DNA extracts. 1B: autoradiography of Southern blot membrane probed with a cloned $13.5 \mathrm{~kb}$ insert containing an aminoglycoside modifying enzyme gene. Unselected variants: 1,3 and 5; variants selected at $128 \mu \mathrm{g} / \mathrm{ml}$ of gentamicin (overnight growth): 2,4 and $6 ; E$. coli $1 / 15$ transconjugant (K12 x K. pneumoniae AS15): 1 and 2; $K$. pneumoniae AS15: 3 and 4; K. pneumoniae MS16: 5 and 6.

pear in the semi-quantitative tests that did not display the amplification phenomenon.

Differently from the antimicrobial sensitivity tests with usual concentrations, the tests using high concentrations showed the parallel rising of

\section{TABLE III}

Evaluation of gene inactivation and co-amplification by sensitivity test using disks with high concentrations of antimicrobial agents

\begin{tabular}{llllllll}
\hline Strains $^{a}$ & \multicolumn{6}{c}{ Inhibition zone diameter $(\mathrm{mm})$ for disks impregnated with highly concentrated antimicrobial agents $b$} \\
\cline { 2 - 7 } & $\mathrm{Gm}^{c}$ & Tri & Cef & Tel & Tc & Cm & Ami \\
\hline A & 16 & 0 & 21 & 0 & 22 & 12 & 12 \\
A32 & 16 & $0(32)$ & 20 & 0 & 23 & 33 & 12 \\
A128 & $13(30)^{d}$ & $0(34)$ & $21(32)$ & 0 & 23 & $13(27)$ & $9(22)$ \\
A2048/1 & $14(25)$ & $0(35)$ & $24(33)$ & 0 & $22(26)$ & $17(29)$ & $8(17)$ \\
A2048/2 & 09 & 0 & 20 & 0 & 24 & 15 & 0 \\
A2048/3 & 10 & 0 & 21 & 0 & 25 & 14 & 0 \\
A2048/5 & 10 & 0 & 20 & 0 & 25 & 16 & 0 \\
\hline
\end{tabular}

a: strain A: not selected Klebsiella pneumoniae AS15 strain; strains A32, A64, A128, A256, A1024, and 2048: AS15 strain selected, respectively, in media with $32,64,128,256,1024$, and $2048 \mu \mathrm{g} / \mathrm{ml}$ of gentamicin. At this later concentration, four different colonies were isolated for testing performed in quadruplicates; $b$ : Gm: gentamicin, TS: trimethoprim-sulphamethoxazole, Cf: cefalotin, Tel: potassium tellurite, Tc: tetracyclin, Cm: chloramphenicol, Ami: amikacin; $c$ : concentrations of impregnated disks: $\mathrm{Gm}, 10 \mathrm{mg} / \mathrm{ml}$, Ts, $50 \mathrm{mg} / \mathrm{ml}$; Cef, $125 \mathrm{mg} / \mathrm{ml}$; Tel, $2.5 \mathrm{mg} / \mathrm{ml} ; \mathrm{Cm}$, $125 \mathrm{mg} / \mathrm{ml}$; Tc, $25 \mathrm{mg} / \mathrm{ml}$; ami, $30 \mu \mathrm{g} / \mathrm{ml}$ (usual concentration); $d$ : numbers into parentheses refer to the display of an additional enlarged inhibition zone, and to the average of a at least two different tests. 
gentamicin resistance and amikacin resistance for the variant strains selected at progressively higher concentrations of gentamicin, indicating an increase of the gene dose (Table III).

The similarity of the frequencies of resistant colony forming units obtained with, or without, previous selection with ampicillin $(100 \mu \mathrm{g} / \mathrm{ml})$ weakens the hypothesis of differences in gentamicin resistance resulting from an eventual loss of the plasmid carrying the probable gene codifying aminoglycoside modifying enzyme, taking into account the coexistence of this gene and the beta lactamase codifying gene (responsible for ampicillin resistance) in that plasmid transferrable through bacterial conjugation.

In regard to gentamicin and amikacin resistance, the increase of the gene dose as a consequence of mutational alterations in the plasmid copy number control mechanism seems unlikely, considering the maintenance of the levels of resistance to other antimicrobials present in the simple transferrable plasmid harbored by the studied strain. Peterson and Rownd (1985) were able to discriminate (by endonuclease restriction analysis) amplification by recombination in pNR1[R100] from the simple increase in copy number of a plasmid mediating resistance to neomycin.

On the other hand, favoring the hypothesis of rearrangements promoted by a specialized genetic element stands the evidence, in the sensitivity diffusion tests, of subpopulations with increased sensitivity to various antimicrobial agents, alongside (for the same original variant) uniformly resistant subpopulations. These subpopulations, possibly indicating insertion events, appear more extensively for two variants selected at high gentamicin concentrations (A128 and A2048/1) and in a more restricted fashion (affecting only trimethoprimsulphamethoxazole resistance) in the A32 strain variant, corroborating a possible random feature for these phenomena.

The hypothesis of plasmid loss in these variants exhibiting subpopulations with increased sensitivity to some antimicrobial agents seems ruled out because of the absence of increased sensitivity to other resistance markers present in the same plasmid (several markers, in the strain variant A128).

We think that the modulation of the resistance may, in fact, be the result of random insertions in the context of the amplification phenomena (Wiedemann et al. 1986). Besides, the occurrence of interruptions in the coding DNA sequences and/or control DNA sequences may be the result of more extensive and drastic recombinations, with accompanying deletions of DNA sequences (Nies et al. 1986). In this sense, it seems corroborative the fact that we have detected, in strains selected at high gentamicin con- centrations $(128 \mu \mathrm{g} / \mathrm{ml})$, occasional alterations in the electrophoretic profiles of the plasmids, determining the appearance of an additional band of lower molecular weights, co-migrating with the chromossomal DNA (Fig. 1, lanes 5 and 6).

We obtained, in hybridization assays, indications of increased gene dose, inferred from stronger signals in the variants (both wild and transconjugant ones) selected at high gentamicin concentrations. The frequency of colony forming units selected at high gentamicin concentrations seems to support the occurrence of resistance amplification phenomenon by cumulative transposition events.

Although the whole probe encompasses a region longer than any potential antimicrobial resistance gene, the highly stringent conditions used in the hybridizations indicate a considerable degree of homology to the plasmidial and chromossomal DNA detected. The hypothesis of gene dose increase is strongly supported by the data presented in Fig. 2B, where more intense hybridization signals can be seen for the strains selected at higher gentamicin concentrations (wild type and transconjugant $E$. coli). The hybridization signal related to the bands (plasmid and chromossomal ones) of the variants not selected at high gentamicin concentrations were, in fact, much less intense than those corresponding to the selected variants. It is important to mention here that the same amount of DNA was loaded on each lane of the gel (visualized by ethidium bromide staining) subjected to Southern blotting transfer, as well as that the hybridization signal related to the chromossomal region, might also have occured in the event of transposition followed by plasmidial rearrangements. However, the breakdown of plasmids originating fragments with lower molecular weights that hybridize at the chromossomal region may not be ruled out.

The possible occurrence of mutations affecting the regulation of genes codifying aminoglycosides modifying enzymes seems unlikely, given the frequency and the regularity of the events, shown at the hybridization experiments.

The most intense signals, relating to the selected variant strains, detected both for the plasmid band and for the chromossome band (or, alternatively, for a plasmid comigrating in the gel with chromossomal fragments) may be due to random transpositions involving both replicons (plasmid and chromossome) as targets indicating a probable conservative event. Anyway, a not negligible homology degree between the probe and the target gene enabled the utilization of the probe as tool for the amplification analysis.

Many resistance genes are transposon-born and have the potential for rapid dispersal through- 
out the bacteria. It is noteworthy that there are several transposons carrying aminoglycosides resistance gene sequences (Schmitt 1986, Lambert et al. 1994, Panaite \& Tolmasky 1998). Site-specific recombination seems to play an important role in the emergence of resistance. Direct repeats are involved in the formation of resistance blocks (Wiedemann et al. 1986) and transposons, single or multiple, are also elements participating in the process of resistance gene blocks formation found in plasmids (Bennett \& Hawkey 1991).

From an epidemiological standpoint, it seems relevant to consider the problem of the resistance codified by bacterial genes expressed at lower levels (i.e., levels lower than those of the "resistance" as accepted for the guidance of therapeutic procedures or antimicrobial use). In these cases, amplification phenomena could lead to therapeutic failure due to the emergence of resistant strains under selective pressure. We have also to consider at least some other aspects of the problem, such as the importance of screening anatomical sites usually colonized for the presence of bacteria that are able to reach the level of subtherapeutical resistance, codified by genes contained in or mobilizable by specialized genetic elements. Another issue concerns the interest in systematic phenotypic studies of the prevalence of strains capable of amplification, prior to molecular analysis. We should also take into account the reversal rates, eventually close to the amplification ones, and that could somehow neutralize its effect making it unclear what are the levels of antimicrobial resistance amplification that may be attainable, posing problems to laboratory detection as well as favoring therapeutic failure. Furthermore, several enterobacterial strains isolated from faeces of newborns from the same hospital unit displayed the potential for aminoglycoside amplification resistance. Such studies could take advantage from simple resources, like selection tests in culture medium with high antibiotic concentrations, allowing the analysis of a greater number of strains of clinical-epidemiological interest.

Judging from the magnitude of the bacterial resistance amplification frequencies found $\left(\sim 10^{-3}\right)$, near to the frequencies described for transposition and site-specific recombinations involving genetic elements associated to resistance (Peterson \& Rownd 1985, Schmitt 1986, Nies et al. 1986), we believe that the cell densitites commonly used for determining the minimum inhibitory concentration may not be large enough to allow the detection of strains capable of amplification. A closer look at the question of bacterial antimicrobial resistance amplification at laboratorial diagnostic level could allow more appropriate measures for the epidemiological control of multiresistance emergence and dissemination.

\section{ACKNOWLEDGEMENTS}

To Dr Maria do Carmo Freire Bastos (Instituto de Microbiologia Prof. Paulo de Góes, UFRJ) for the critical review of the manuscript.

\section{REFERENCES}

Baquero F, Negri MC, Morosini MI, Blazquez J 1997. The antibiotic selective process: concentration-specific amplification of low-level resistant populations. Ciba Found Symp 207: 93-105.

Bauer AW, Kirby WM, Sherris JC, Turck M 1966. Antibiotic susceptibility testing by a standardized single disk method. Am J Clin Pathol 45: 493-496.

Bennett PM, Hawkey PM 1991. The future contribution of transposition to antimicrobial resistance. $J$ Hosp Infect 18 (Suppl. A): 211-221.

Casewell M, Phillips I 1977. Hands as route of transmission for Klebsiella species. Br Med J 2: 13151317.

Chopra I 1992. Efflux-based antibiotic resistance mechanisms: the evidence for increasing prevalence. $J$ Antimicrob Chemother 30: 737-739.

Datta N, Hughes VM 1983. Plasmids of the same Inc groups in Enterobacteria before and after the medical use of antibiotics. Nature 306: 616-617.

Feinberg AP, Vogelstein B 1983. A technique for radiolabeling DNA restriction endonuclease fragments to high specific activity. Anal Biochem 132: 6-13.

Harihan R, Weinstein RA 1996. Enterobacteriaceae, p. 345-366. In CG Mayhall, Hospital Epidemiology and Infection Control, Williams \& Wilkins, Baltimore.

Jacoby GA, Archer GL 1991. New mechanisms of bacterial resistance to antimicrobial agents. $N$ Engl $J$ Med 324: 601-612.

Kado CI, Liu ST 1981. Rapid procedure for detection and isolation of large and small plasmids. J Bacteriol 145: 1365-1373.

Lambert T, Ploy MC, Courvalin P 1994. A spontaneous point mutation in the aac $\left(6^{\prime}\right)-\mathrm{Ib}^{\prime}$ gene results in altered substrate specificity of aminoglycoside 6'-Nacetyltransferase of a Pseudomonas fluorescens strain. FEMS Microbiol Lett 115: 297-304.

Maniatis T, Fritsch EF, Sambrook J 1982. Molecular Cloning: A Laboratory Manual, Cold Spring Harbor Laboratory Press, New York, 545 pp.

Martinez-Salazar JM, Alvarez G, Gomez-Eichelmann MC 1986. Frequency of four classes of tetracycline resistance determinants in Salmonella and Shigella spp. clinical isolates. Antimicrob Agents Chemother 30: 630-631.

Nies BA, Meyer JF, Wiedemann B 1986. Role of transposition and homologous recombination in the rearrangement of plasmid DNA. J Antimicrob Chemother 18 (Suppl. C): 35-41.

Panaite DM, Tolmasky ME 1998. Characterization of mutants of the 6'-N-acetyltransferase encoded by the multiresistance transposon Tn1331: effect of Phen171-to-Leu171 and Tyr80-to-Cys80 substitutions. Plasmid 39: 123-133.

Pereira JAA 1990. Estudo Epidemiológico da Infecção Hospitalar e Resistência a Antimicrobianos e ao Telurito de Potássio em Enterobacteriaceae, com 
Referência Especial a Klebsiella pneumoniae, $\mathrm{PhD}$ Thesis, Instituto de Microbiologia, UFRJ, $174 \mathrm{pp}$.

Peterson BC, Rownd RH 1985. Drug resistance gene amplification of plasmid NR1 derivatives with various amounts of resistance determinant DNA. $J$ Bacteriol 161: 1042-1048.

Phillips I, French GL 1996. Antimicrobial resistance in hospital flora and nosocomial infections, p. 980-999. In CG Mayhall, Hospital Epidemiology and Infection Control, Williams \& Wilkins, Baltimore.

Schmitt R 1986. Molecular biology of transposable elements. J Antimicrob Chemother 18 (Suppl. C): 25-34.

Shalaes DM, Rice LB 1996. Mechanisms of bacterial resistance to antimicrobial agents, p. 965-980. In CG Mayhall, Hospital Epidemiology and Infection Control, Williams \& Wilkins, Baltimore.

Shaw KJ, Rather PN, Hare RS, Miller GH 1993. Molecular genetics of aminoglycoside resistance genes and familial relationships of the aminoglycoside- modifying enzymes. Microbiol Rev 57: 138-163.

Silver LL, Bostian KA 1993. Discovery and development of new antibiotics: the problem of antibiotic resistance. Antimicrob Agents Chemother 37: 377383.

Thompson R 1986. R plasmid transfer. J Antimicrob Chemother 18 (Suppl. C): 13-23.

Tolmasky ME, Chamorro RM, Crosa JH, Marini PM 1988. Transposon-mediated amikacin resistance in Klebsiella pneumoniae. Antimicrob Agents Chemother 32: 1416-1420.

Vieira LA, Castro EAR, Duarte JLB, Pinheiro SR, Suassuna I, Pereira JAA 1999. Colonização intestinal de recém-natos por enterobactérias multiressistentes a antimicrobianos em unidade neonatal. $J$ Pediatr (Rio J) 75: 83-90.

Wiedemann B, Meyer JF, Zuhlsdorf MT 1986. Insertions of resistance genes into Tn21-like transposons. J Antimicrob Chemother 18 (Suppl. C): 85-92. 